\title{
A preliminary study of Patient Dignity Inventory validation among patients hospitalized in an acute psychiatric ward
}

This article was published in the following Dove Press journal:

Neuropsychiatric Disease and Treatment

23 January 2017

Number of times this article has been viewed

\author{
Rosaria Di Lorenzo' \\ Giulio Cabri² \\ Eleonora Carretti ${ }^{3}$ \\ Giacomo Galli ${ }^{4}$ \\ Nina Giambalvo ${ }^{4}$ \\ Giulia Rioli ${ }^{4}$ \\ Serena Saraceni $i^{4}$ \\ Giulia Spiga ${ }^{4}$ \\ Cinzia Del Giovane ${ }^{5}$ \\ Paola Ferri ${ }^{6}$ \\ 'Mental Health Department, \\ Service of Psychiatric Diagnosis \\ and Treatment in NOCSAE General \\ Hospital, ${ }^{2}$ Private Accredited \\ Psychiatric Hospital villa lgea, \\ Modena, ${ }^{3}$ Nursing Home of Rubiera, \\ Reggio Emilia, ${ }^{4}$ Department of \\ Diagnostic, Clinical and Public Health \\ Medicine, University of Modena \\ and Reggio Emilia, ${ }^{5} \mathrm{PhD}$ Statistics \\ Unit, Department of Diagnostic, \\ Clinical and Public Health Medicine, \\ ${ }^{6}$ Department of Diagnostic, Clinical \\ and Public Health Medicine, \\ University of Modena and Reggio \\ Emilia, Modena, Italy
}

Purpose: To investigate the perception of dignity among patients hospitalized in a psychiatric setting using the Patient Dignity Inventory (PDI), which had been first validated in oncologic field among terminally ill patients.

Patients and methods: After having modified two items, we administered the Italian version of PDI to all patients hospitalized in a public psychiatric ward (Service of Psychiatric Diagnosis and Treatment of a northern Italian town), who provided their consent and completed it at discharge, from October 21, 2015 to May 31, 2016. We excluded minors and patients with moderate/severe dementia, with poor knowledge of Italian language, who completed PDI in previous hospitalizations and/or were hospitalized for $<72$ hours. We collected the demographic and clinical variables of our sample $(n=135)$. We statistically analyzed PDI scores, performing Cronbach's alpha coefficient and principal factor analysis, followed by orthogonal and oblique rotation. We concomitantly administered to our sample other scales (Hamilton Rating Scales for Depression and Anxiety, Global Assessment of Functioning and Health of the Nation Outcome Scales) to analyze the PDI concurrent validity.

Results: With a response rate of $93 \%$, we obtained a mean PDI score of 48.27 ( \pm 19.59 SD) with excellent internal consistency (Cronbach's alpha coefficient $=0.93$ ). The factorial analysis showed the following three factors with eigenvalue $>1$ (Kaiser's criterion), which explained $>80 \%$ of total variance with good internal consistency: 1) "Loss of self-identity and social role", 2) "Anxiety and uncertainty for future" and 3) "Loss of personal autonomy". The PDI and the three-factor scores were statistically significantly positively correlated with the Hamilton Scales for Depression and Anxiety but not with other scale scores.

Conclusion: Our preliminary research suggests that PDI can be a reliable tool to assess patients' dignity perception in a psychiatric setting, until now little investigated, helping professionals to improve quality of care and patients to accept treatments.

Keywords: dignity experience, Patient Dignity Inventory, patients hospitalized in a psychiatric ward, factor analysis, validation study, dignity distress measurement

\section{Introduction}

\section{Dignity in health care setting}

Dignity is a complex concept that belongs not only to many fields of knowledge such as philosophy, religion, medicine, law, social sciences and ethics but also to common sense. ${ }^{1,2}$ The meaning of dignity has changed in accordance with historical and cultural evolution of human societies. ${ }^{3,4}$ In the contemporary age, dignity is considered as a fundamental and universal human right, as the Universal Declaration of Human Rights (ONU 1948) states: "All human beings are born free and equal in dignity and
Correspondence: Rosaria Di Lorenzo Mental Health Department, Service of Psychiatric Diagnosis and Treatment in NOCSAE General Hospital, via P. Giardini, I355, 4I I 26 Baggiovara (Modena), Az-Usl, Modena, Italy Email saradilorenzol@alice.it 
rights for participation in the common humanity, regardless of status, race, social status and economic, physical illness and/or mental". 5,6

More recently, many authors ${ }^{7-9}$ have investigated dignity in health care settings, highlighting that both hospital and community care are places at risk for dignity damage due to the vulnerable conditions of patients. In particular, Jacobson ${ }^{9}$ showed that the experience of dignity can explain the mutual relationship between health and human rights, suggesting that, in modern times, dignity represents a key concept for good professional practice in many fields of medicine, particularly in palliative and long-term care. , $^{910}$ The author identified the following two main forms of dignity: "human dignity", which represents a universal value of the human race, and "social dignity", seen as the product of the interaction between individuals and society, with its culture and tradition. ${ }^{11}$ The violation of dignity can result from asymmetrical relationships or vulnerable conditions such as disabling diseases and can induce harmful consequences for patients, such as feelings of fear, humiliation, embarrassment, shock, frustration, insecurity, apathy, isolation and depression. ${ }^{9}$ On the contrary, the safeguarding of a patient's dignity can promote "a sense of well-being", improve adherence to treatments and reduce the risk for institutional regression and dependence. ${ }^{12-14}$ Several other authors agree on the idea that patients' dignity perception can be strongly conditioned by various factors, such as physical environment, behavior and habits of health care staff, therapeutic alliance, staff organization and autonomy of the patient. ${ }^{15-19}$

In many fields of medicine, the risk for dignity violation can be represented by extreme medical procedures, which offer increasing chances of survival at the price of conditions detrimental to privacy and intimacy. ${ }^{20}$ At the same time, in other fields, such as psychiatry, isolation, stigmatization and coercion are risk conditions for dignity loss. ${ }^{21}$ In this regard, the World Health Organization (WHO), during the "World Mental Health Day" (October 10, 2015), stated: “All over the world, thousands of people with mental health problems are deprived of their human rights [...] being discriminated, stigmatized and marginalized". ${ }^{22}$ The WHO initiative aimed at increasing all useful activities to ensure a dignified life for people with mental disorders ${ }^{23}$ arose from the need for an ethical framework for decision making and treatments in caring for vulnerable psychiatric patients. ${ }^{24}$ In fact, protecting the rights of people with mental disabilities by respecting "their dignity, and independence, and their freedom to make their own choices" was recently fostered by many authors. ${ }^{25-29}$ Health care professionals have an important role "to play as advocates for equality, non-discrimination and justice" and promote dignity and respect among patients affected by a mental disease "on an equal basis with others". ${ }^{25-28}$ However, so far only a little research is available on this topic in psychiatry, as shown by a recent study that focused on dignity in health contexts. ${ }^{21}$ The previous studies that focused on dignity in mental health care were based almost exclusively on semistructured interviews, which investigated the staff and not the patients' experience, producing limited or not exhaustive results. ${ }^{29,30}$ Lindwall et al, ${ }^{31}$ who interviewed members of the Mental Health Department of Karlstad University in Sweden, showed that patients' dignity can be maintained only if professionals work according to ethical principles and sense of responsibility, whereas it can be violated when therapeutic alliance fails and conflicts with patients are present. Skorpen et al, ${ }^{32}$ interviewing inpatients of a psychiatric ward of the University of Solna in Stockholm, found that patients' individual resources are essential to preserve their personal identity, dignity and autonomy, particularly in situations such as hospitalizations that can induce dependence on others. Gustafsson et $\mathrm{al}^{33}$ administered interviews to the staff of a forensic psychiatric facility and highlighted that the preservation of dignity could be achieved by an approach toward patients focused on "protection", "respect" and "fraternal humanity". In another study, Gustafsson et $\mathrm{al}^{34}$ showed that dignity in a psychiatric ward for involuntary admissions can be abused both due to an authoritarian behavior and neglect by professionals and in case of organizational problems that did not permit respectful conditions for patient privacy.

\section{Patient Dignity Inventory}

A tool for detecting the patient's subjective perception of dignity was developed by Chochinov et al, the Patient Dignity Inventory (PDI), in accordance with his model of care for terminally ill patients, called Dignity Therapy. ${ }^{35,36}$ This approach is based on attitudes of therapeutics: attitude, behavior, compassion and dialog (ABCD like the emergency model), aimed at ensuring the preservation of a patient's dignity as "an essential element in the treatment, independent of clinical and demographic factors". ${ }^{37}$ After evaluating a wide range of physical, psychological, spiritual and existential factors, they identified three macro-areas, each one associated with the 25 items that formed this questionnaire: 1) illness-related concerns that are formed by two other dimensions, level of independence and symptoms distress; 2) dignity-conserving repertoire formed by two other dimensions, dignity-conserving perspectives and practices; and 3) social dignity inventory. The statistical analysis applied 
to the PDI demonstrated excellent internal consistency; the test-retest procedure showed a high degree of coherence; at factor analysis, a five-factor solution, which accounted for $58 \%$ of the overall variation, was obtained..$^{36}$ The concurrent validity of different factors was tested with different psychometric instruments that measured many dimensions such as suffering, well-being, depression, anxiety and quality of life items. ${ }^{36}$ Successively, a study analyzed the construct of personal dignity, assessing the validity of the PDI items in a large cohort of people at the end of life in the Netherlands. ${ }^{38}$

The PDI was validated in its Italian version in the oncology field, where it showed a good internal consistency (Cronbach's alpha coefficient $=0.96$ ) with a one-factor solution that explained $48 \%$ of variance. ${ }^{39}$ Later, it was validated in its German ${ }^{40}$ and Spanish $^{41}$ versions in oncologic care contexts. The German study of validation highlighted a four-factor solution, accounting for $71 \%$ of the overall variance: Loss of Sense of Worth and Meaning, Anxiety and Uncertainty, Physical Symptom Distress and Body Image, and Loss of Autonomy with high internal consistencies ranging from Cronbach's alpha 0.80-0.95. ${ }^{40}$ Statistically significant positive associations between PDI scales and concurrent measures of distress (Generalized Anxiety Disorder 7-item scale, Beck Hopelessness Scale and Demoralization Scale) and significant negative correlation with the European Organisation for Research and Treatment of Cancer Quality of Life Questionnaire-Core were evidenced by the German study. ${ }^{40}$ The Spanish study of PDI validation indicated excellent reproducibility and obtained a three-factor solution at factor analysis that accounted for $79.4 \%$ of the variance: Psychological and Existential Distress, Physical Symptoms and Dependency, and Social support. ${ }^{41}$ The Spanish authors correlated PDI with other scales, Edmonton Symptom Assessment System, Hospital Anxiety and Depression Scale and Functional Assessment of Chronic Illness Therapy-Spiritual Well-Being instruments, highlighting positive significant relationship with the symptom scales and a negative significant correlation with the functioning scale. ${ }^{41}$ The PDI was also administered to patients hospitalized in an Iranian intensive cardiology unit, where it again showed good validity and reliability in assessing patient dignity perception. ${ }^{42}$ The Iranian study evidenced a four-factor solution, labeled Loss of Human Dignity, Emotional Distress and Uncertainty, Changes in Ability and Mental Picture and Loss of Independence, with high internal consistence (the Cronbach's alpha for PDI was 0.85 and for each factor ranged from 0.80 to 0.91$).{ }^{42}$ To determine construct validity, the Iranian study correlated the PDI scores with Beck Anxiety Inventory, Beck Depression Inventory, Beck Hopelessness Scale and SF-36 Health Survey, highlighting a significant positive correlation between the overall score of the PDI and the factors obtained with the Beck scales for anxiety and depression and a negative correlation with SF-36 Health Survey.

These results were further developed in recent research ${ }^{43}$ among in- and outpatients affected by non-oncologic but terminal conditions, which highlighted similar loss of dignity, ranged from moderate to severe, among the study populations affected by different disorders. These data suggest the universal psychometric properties of PDI in evaluating dignity of patients coming from different cultures and suffering from different pathologies.

The use of PDI in a field totally different from that for which it was developed and validated can be justified not only by heuristic aims, which are, however, desired by the author of the questionnaire, ${ }^{36}$ but also by similar dignity issues shared by neoplastic and other disorders, which, especially if severe, can represent risk conditions for dignity loss due to dramatic disruption of life conditions. In this regard, the five domains investigated by PDI belong to stressful conditions related to most serious and disabling illness, as some recent studies have highlighted in different fields of medicine. ${ }^{42,43}$ In psychiatry, the importance of being able to measure dignity stems from the need to ensure respectful treatments in conditions where the boundaries between individual rights and the public interest may conflict. ${ }^{21}$ In particular, the need for having their dignity respected can be felt by inpatients involuntarily hospitalized in a psychiatric ward due to acute and sometimes extreme situations, such as unavoidable danger for the patients themselves and others. In these conditions, patients can feel their privacy and freedom being violated, experiencing a catastrophic change in their life. Moreover, the hospitalization in psychiatry, although necessary, can frequently induce behavioral regression and institutional dependency, both risk conditions for dignity loss. ${ }^{44,45}$ Up to now, although there is the need for investigating dignity among patients affected by psychiatric disorders, no instrument for assessing dignity has been tested in psychiatry.

\section{Aim of the study}

The objective of this preliminary research is to validate the Italian version of the PDI in an acute psychiatric ward in order to assess the validity of this instrument in measuring the perception of dignity among inpatients affected by psychiatric disorders. 


\section{Patients and methods Study design and procedures}

This research is an experimental study on the use of PDI in a group of patients affected by psychiatric disorders and hospitalized in an acute ward. The questionnaire, originally developed by Prof HM Chochinov et $\mathrm{al}^{36}$ in 2008, consists of 25 items evaluated on a five-solution scale ranging from "It is not a problem", equivalent to a score of 1 , to "It's a problem that overwhelms me", associated with the maximum score of 5 . The total PDI score is ranged between 25 and 125 points.

After an interactive discussion among researchers, we adopted the Italian version of PDI, initially validated in the oncologic field, ${ }^{39}$ slightly modifying only two items:

- No 3: "Physically distressing symptoms" was changed to "Experiencing physically distressing symptoms (such as pain, shortness of breath, nausea) as drug adverse effects"

- No 17: "Concerns regarding spiritual life" was changed to "Concern that my spiritual life is not meaningful".

Item No 3 was changed since physically distressing symptoms are not the most causes of distress or discomfort among patients affected by psychiatric diseases, unlike other organic disorders, as clinical experience suggests. Items No 17 was changed in order to avoid the connotation of end-of-life conditions present in the original version, not appropriate in a psychiatric setting.

We concomitantly administered additional scales in order to evaluate the concurrent validity with the PDI by validated measures of the main domains of the questionnaire (distress, demoralization, anxiety, depression, hopelessness, functional aspects of life), as indicated by the author of PDI and as adopted in other studies on validation of the

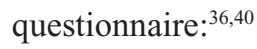

- Hamilton Rating Scale for Depression (Ham-D), a multiple-item questionnaire designed for adults, aimed at rating severity of depression, investigating mood, feelings of guilt, suicide ideation, insomnia, agitation or retardation, anxiety, weight loss and somatic symptoms. It is considered the "gold standard" for rating depression in clinical research. The total score of 17 items is classified into: $0-7=$ Normal; $8-13=$ Mild; $14-18=$ Moderate; $19-22=$ Severe $>23=$ Very Severe Depression; ${ }^{46}$ Hamilton Anxiety Rating Scale (Ham-A), widely used by clinicians, is composed of 14 items designed to evaluate the severity of anxiety, assessing many symptoms related to anxiety rated on a scale ranged from zero (the least severe) to four (the most severe). ${ }^{47}$
- Global Assessment of Functioning (GAF) is a numeric scale aimed at subjectively rating the social, occupational and psychological functioning, with a score ranged from 100 (extremely high functioning) to 1 (severely impaired). ${ }^{48}$

These scales were chosen because they are easy and commonly used in psychiatry. Moreover, we evaluated the correlation of PDI with the Health of the Nation Outcome Scales (HoNOS), ${ }^{49}$ which is used in our ward at the admission and discharge of patients, according to local guidelines. It is a clinician-rated instrument comprising 12 simple scales measuring behavior, impairment, symptoms and social functioning for adult patients.

The PDI was self-administered by all patients, except one who was helped for visual difficulties.

The PDI questionnaire was given to hospitalized patients by ward medical staff in a period ranging from 3 days before to the time of patient discharge.

Data collection was conducted between October 21, 2015 and May 31, 2016.

\section{Participants}

We decided that the minimum sample size for performing factor analysis was represented by the number of subjects larger by five times the number of variables, according to "the rule of 5" concerning the subjects-to-variables (STV) ratio. ${ }^{50,51}$

The sample was collected among all patients admitted to the acute public psychiatric ward, Service of Psychiatric Diagnosis and Treatment (SPDT), of a northern Italian town. This 15-bed ward, as required by Law 180 of 23/05/1978 (later included in Law 833 of 12/23/1978), is located in a General Hospital and caters for patients with acute mental disorders requiring hospital care in voluntary and involuntary treatment from the related catchment areas $(\sim 500,000$ inhabitants). SPDT is the inpatient care facility, closely connected to outpatient care of both Mental Health Service and Substance Use Service. At discharge, most patients are sent to outpatient services for continuing care programs. However, because only short hospitalizations are allowed in SPDT, those patients who need to prolong inpatient voluntary treatment are transferred to other psychiatric wards in private hospitals affiliated with Mental Health Service, as mandated by the regional Mental Health Organization Protocol.

We collected our sample according to inclusion and exclusion criteria.

Inclusion criteria: all patients should be

- able to understand the questionnaire,

- able to complete it autonomously, 
- able to give us their informed written consent,

- hospitalized $>72$ hours and having never completed the questionnaire before.

Exclusion criteria:

- Minor age

- Moderate or severe mental retardation

- Dementia with severe cognitive impairment (Minimal Mental State Examination $<24)^{52}$

- Poor knowledge of Italian language

- PDI compilation in previous hospitalizations

- Hospitalization $<72$ hours

We collected demographic and clinical variables of our sample from SPDT medical records, the electronic database used in the ward (Hospital Information System), and, when necessary, information was provided by each patient's referring psychiatrists.

Demographic variables included gender, age, nationality, marital status, education, work activity, family and living conditions and social and economic conditions.

Clinical variables included psychiatric illness duration, psychiatric hospitalizations in the previous 10 years, psychiatric diagnosis at discharge (International Classification of Diseases, 9th Revision, Clinical Modification [ICD-9-CM]), ${ }^{53}$ organic comorbidity, substance abuse, duration and state of hospitalization and destination at discharge.

This research was conducted according to the principles of the Declaration of Helsinki and according to good clinical practice. We obtained the approval for this study from the local ethics committee (Comitato Etico Provinciale di Modena Azienda Ospedaliero-Universitaria di Modena) on October 21, 2015 (3565 Protocol 173/15 Practice) and the authorization of our Department of Mental Health. A written informed consent was one of the criteria for inclusion in this study.

\section{Validity}

We previously assessed the PDI content and face validity. The content validity was discussed among the researchers, who concluded that the dimensions investigated by the PDI can also be shared by patients affected by psychiatric diseases, especially if severe and hospitalized; later, we asked Prof HM Chochinov his opinion about the implementation of this questionnaire in psychiatry, obtaining his approval. The face validity was initially assessed by the first 20 patients of our sample: we evaluated their capacity to understand the questionnaire and the level of difficulty in comprehending the concept of dignity, independently from their educational levels and disorders' specificity. Since these aspects resulted good, we decided to continue with our validation study. To assess the structural validity, we investigated the internal consistency of PDI and explored its dimensions by factor analysis. ${ }^{54}$

\section{Statistical analysis}

Descriptive statistical analysis was performed for demographic and clinical variables: mean \pm standard deviation (SD) and paired and unpaired $t$-test for continuous data; percentages and chi-square for categorical data.

The internal consistency of the PDI was evaluated by the Cronbach's alpha coefficient. ${ }^{55}$ We evaluated the internal structure of the PDI using the conventional approach of principal factor analysis followed by orthogonal rotation (varimax), which assumed that the factors in the analysis are uncorrelated. ${ }^{56,57}$ The factors highlighted by the orthogonal rotation were selected according to the eigenvalue $>1$ for each factor (Kaiser's criterion), ${ }^{58}$ later confirmed by the scree plot graphical feedback.

The items with factor loadings $>0.40$ on a given dimension were identified as good indicators of each factor. To verify the appropriateness of the orthogonal rotation analysis, we applied the oblique rotation of the factors (promax), which allowed the assessment of the factors' interdependence, assuming that the factors were correlated.

To assess the appropriateness of our sample for doing factor analysis, we applied the Kaiser-Meyer-Olkin (KMO) measure, which evaluates the sampling adequacy in numerosity, and the Bartlett's test of sphericity, which tests whether the data come from normal distribution with zero covariances. ${ }^{59}$

The PDI concurrent validity was analyzed by means of the correlation with all other scale scores (Spearman and Kendall tests).

Similarly, to examine internal consistency and concurrent validity of each factor previously identified, we calculated the Cronbach's alpha coefficient for each factor and analyzed the correlation with all other scale scores.

Data were analyzed using STATA version $12 .^{60}$

\section{Results}

In our study, the response rate to PDI was 93\% since it was administered to 145 patients admitted to our ward but 10 of them $(7 \%)$ refused to participate in the research.

Our sample was composed of 135 patients, 70 females $(52 \%)$ and 65 males (48\%), with an STV ratio of 5.4 . The demographic variables are shown in Table 1. Our patients presented a mean age of $43.30 \pm 14.42$ years, were 
Table I Descriptive of demographic variables

\begin{tabular}{|c|c|c|c|}
\hline Variables & $\begin{array}{l}\text { Males } \\
n=65 \\
(48 \%)\end{array}$ & $\begin{array}{l}\text { Females } \\
n=70 \\
(52 \%)\end{array}$ & $\begin{array}{l}\text { Total } \\
n=135 \\
(100 \%)\end{array}$ \\
\hline \multicolumn{4}{|l|}{ Age $(m \pm S D)$} \\
\hline Years & $42.90 \pm 15.32$ & $43.67 \pm 13.64$ & $43.30 \pm 14.42$ \\
\hline \multicolumn{4}{|l|}{ Nationality, n (\%) } \\
\hline Italian & $56(86)$ & $62(89)$ & II 8 (88) \\
\hline European extra-Italian & $I(2)$ & $I(I)$ & $2(I)$ \\
\hline Extra-European & $8(12)$ & $7(10)$ & $15(11)$ \\
\hline \multicolumn{4}{|l|}{ Marital status, n (\%) } \\
\hline Single & $46(7 I)$ & $33(47)$ & $79(59)$ \\
\hline Married & $15(23)$ & $20(29)$ & $35(26)$ \\
\hline Divorced/widowed & $4(6)$ & $17(24)$ & $21(15)$ \\
\hline \multicolumn{4}{|l|}{ Schooling, n (\%) } \\
\hline Primary school & $9(14)$ & $8(11)$ & $17(12)$ \\
\hline Secondary school & $23(35)$ & $21(30)$ & $44(33)$ \\
\hline High school & $27(42)$ & $28(40)$ & $55(4 I)$ \\
\hline Degree & $6(9)$ & $13(19)$ & $19(14)$ \\
\hline \multicolumn{4}{|l|}{ Work activity, $\mathrm{n}(\%)$} \\
\hline Employed & $21(32)$ & $24(34)$ & $45(33)$ \\
\hline Unemployed & $34(52)$ & $26(37)$ & $60(44)$ \\
\hline Retired & $5(8)$ & $12(17)$ & $17(13)$ \\
\hline Others & $5(8)$ & $8(\mathrm{II})$ & $13(10)$ \\
\hline \multicolumn{4}{|c|}{ Family and surrounding, $\mathrm{n}(\%)$} \\
\hline Single & $14(22)$ & $25(36)$ & $39(29)$ \\
\hline Parental family & $35(54)$ & $16(23)$ & $51(38)$ \\
\hline Marital family & $13(20)$ & $27(39)$ & $40(30)$ \\
\hline $\begin{array}{l}\text { Community/ } \\
\text { residential facility }\end{array}$ & $3(5)$ & $2(3)$ & $5(3)$ \\
\hline \multicolumn{4}{|c|}{ Social and economic condition, $\mathrm{n}(\%)$} \\
\hline Sufficient & $55(85)$ & $58(83)$ & II 3 (84) \\
\hline Insufficient & $10(15)$ & $12(17)$ & $22(16)$ \\
\hline
\end{tabular}

Abbreviations: $\mathrm{m}$, mean; $\mathrm{SD}$, standard deviation.

prevalently Italians (88\%), single (59\%), unemployed (44\%) and had attended high school (41\%), with the following statistically significant differences between the two genders: males more frequently were single (71\%) and lived with their family of origin (54\%), whereas females more often were married (29\%) (Pearson's $\chi^{2}=11.24$, $P=0.010)$ and lived with their acquired family (39\%) (Pearson's $\chi^{2}=15.12, P=0.002$ ).

A descriptive analysis of the clinical variables is reported in Table 2. Our patients more prevalently suffered from schizophrenia disorders and other psychoses (43\%) from a long period $(9.38 \pm 9.34$ years on average). The abuse substance comorbidity was statistically significantly prevalent among males in comparison to females (Pearson's $\left.\chi^{2}=4.62, P=0.032\right)$. The most prevalent state of treatment was voluntary $(53 \%)$ with a statistically significant prevalence among females (Pearson's $\chi^{2}=4.78, P=0.029$ ). The mean GAF score ( $72.37 \pm 14.81 \mathrm{SD})$ indicated that our sample was composed of patients with a discrete degree of autonomy and
Table 2 Descriptive of clinical variables

\begin{tabular}{|c|c|c|c|}
\hline Variables & $\begin{array}{l}\text { Males } \\
n=65 \\
(48 \%)\end{array}$ & $\begin{array}{l}\text { Females } \\
\mathbf{n}=\mathbf{7 0} \\
\mathbf{( 5 2 \% )}\end{array}$ & $\begin{array}{l}\text { Total } \\
n=135 \\
(100 \%)\end{array}$ \\
\hline \multicolumn{4}{|c|}{ Psychiatric illness duration $(m \pm S D)$} \\
\hline Years & $9.17 \pm 9.72$ & $9.58 \pm 9.03$ & $9.38 \pm 9.34$ \\
\hline \multicolumn{4}{|c|}{ Psychiatric hospitalizations in the previous 10 years $(m \pm S D)$} \\
\hline Number & $2.53 \pm 3.67$ & $2.75 \pm 2.68$ & $2.65 \pm 3.19$ \\
\hline \multicolumn{4}{|c|}{ Psychiatric diagnosis at discharge (ICD-9-CM), n (\%) } \\
\hline $\begin{array}{l}\text { Schizophrenic and other } \\
\text { psychotic disorders }\end{array}$ & $25(38)$ & $33(47)$ & $58(43)$ \\
\hline $\begin{array}{l}\text { Bipolar disorders, manic } \\
\text { episode }\end{array}$ & $12(18)$ & $12(17)$ & $24(18)$ \\
\hline Depressive disorders & $9(14)$ & $8(11)$ & $17(12)$ \\
\hline Personality disorders & $17(26)$ & $14(20)$ & $31(23)$ \\
\hline Others & $2(3)$ & $3(4)$ & $5(4)$ \\
\hline \multicolumn{4}{|l|}{ Organic comorbidity, n (\%) } \\
\hline Present & $25(38)$ & $26(37)$ & $5 \mathrm{I}(38)$ \\
\hline Absent & $40(62)$ & $44(63)$ & $84(62)$ \\
\hline \multicolumn{4}{|l|}{ Substance abuse, n (\%) } \\
\hline Present & $26(40)$ & $16(23)$ & $42(31)$ \\
\hline Absent & $39(60)$ & $54(77)$ & $93(69)$ \\
\hline \multicolumn{4}{|c|}{ Duration of hospitalization $(\mathrm{m} \pm \mathrm{SD}$ ) } \\
\hline Days & $13.04 \pm 9.7$ & $16 \pm 14.39$ & $|4.57 \pm| 2.4 \mid$ \\
\hline \multicolumn{4}{|l|}{ State of hospitalization, $\mathrm{n}(\%)$} \\
\hline IT & $24(37)$ & $39(56)$ & $63(47)$ \\
\hline VT & $41(63)$ & 31 (44) & $72(53)$ \\
\hline \multicolumn{4}{|c|}{ Destination at discharge, $\mathrm{n}(\%)$} \\
\hline Home & $39(60)$ & $45(64)$ & $84(62)$ \\
\hline $\begin{array}{l}\text { Transfer to private } \\
\text { hospital }\end{array}$ & $21(32)$ & $20(29)$ & $4 I(30)$ \\
\hline $\begin{array}{l}\text { Transfer to community } \\
\text { or residential facilities }\end{array}$ & $5(8)$ & $5(7)$ & $10(8)$ \\
\hline
\end{tabular}

Abbreviations: $\mathrm{m}$, mean; SD, standard deviation; ICD-9-CM, International Classification of Diseases, 9th Revision, Clinical Modification; IT, involuntary treatment; VT, voluntary treatment.

functioning. The difference between the HoNOS scores at admission (24.10 $\pm 8.33 \mathrm{SD})$ and at discharge (17.16 \pm 6.43 SD) was statistically significant $(t=7.65, P=0.000$, paired $t$-test), indicating an overall clinical improvement of patients at discharge.

Regarding the administration of the PDI, all patients found it easy to read and to complete it autonomously, but one patient who required assistance in reading and compilation of PDI due to vision problems.

Our results showed a total PDI mean score of 48.27 ( $\pm 19.59 \mathrm{SD})$, with single-item score rated an average value inferior to 3 , as shown in Table 3 . The 25 items of the PDI showed excellent internal consistency with a Cronbach's alpha coefficient equal to or greater than 0.93 for both individual item and total score of PDI (Table 3). At our exploratory factor analysis, we obtained the initial factors (the largest 10 factors are summarized with their eigenvalues and percentage of variance in Table 4). 
Table 3 PDI score, inter-item correlations and Cronbach's alpha coefficient in our sample

\begin{tabular}{|c|c|c|c|c|c|}
\hline \multicolumn{2}{|c|}{ PDI items } & \multirow{2}{*}{$\begin{array}{l}\text { Mean } \pm \text { SD } \\
1.54 \pm 1.09\end{array}$} & \multirow{2}{*}{$\begin{array}{l}\text { Min-Max } \\
-5\end{array}$} & \multirow{2}{*}{$\begin{array}{l}\text { Item-test } \\
\text { correlation } \\
0.4638\end{array}$} & \multirow{2}{*}{$\begin{array}{l}\text { Cronbach's } \\
\text { alpha coefficient } \\
0.9350\end{array}$} \\
\hline I & $\begin{array}{l}\text { Not being able to carry out tasks associated with daily } \\
\text { living (eg, washing myself, getting dressed) }\end{array}$ & & & & \\
\hline 2 & $\begin{array}{l}\text { Not being able to attend to my bodily function } \\
\text { independently (eg, needing assistance with toileting-related } \\
\text { activities) }\end{array}$ & $1.39 \pm 0.89$ & $\mathrm{I}-5$ & $0.467 \mid$ & 0.9350 \\
\hline $3^{*}$ & $\begin{array}{l}\text { Experiencing physically distressing symptoms (such as pain, } \\
\text { shortness of breath, nausea) as drug adverse effects }\end{array}$ & $1.98 \pm 1.18$ & $1-5$ & 0.4378 & 0.9354 \\
\hline 4 & Feeling that how I look to others has changed significantly & $1.88 \pm 1.20$ & $1-5$ & 0.6008 & 0.9329 \\
\hline 5 & Feeling depressed & $2.33 \pm 1.44$ & $1-5$ & 0.6247 & 0.9326 \\
\hline 6 & Feeling anxious & $2.26 \pm 1.34$ & $1-5$ & 0.6245 & 0.9326 \\
\hline 7 & Feeling uncertain about my illness and treatment & $1.91 \pm 1.17$ & $1-5$ & 0.6523 & 0.9322 \\
\hline 8 & Worrying about my future & $2.57 \pm 1.45$ & $1-5$ & 0.6413 & 0.9324 \\
\hline 9 & Not being able to think clearly & $1.84 \pm 1.25$ & $1-5$ & 0.7205 & 0.9311 \\
\hline 10 & Not being able to continue with my usual routines & $2.19 \pm 1.39$ & $1-5$ & 0.5357 & 0.9340 \\
\hline II & Feeling like I am no longer who I was & $1.78 \pm 1.16$ & $1-5$ & 0.7300 & 0.9309 \\
\hline 12 & Not feeling worthwhile or valued & $1.90 \pm 1.20$ & $1-5$ & 0.7056 & 0.9314 \\
\hline 13 & $\begin{array}{l}\text { Not being able to carry out important roles (eg, spouse, } \\
\text { parent) }\end{array}$ & $2.05 \pm 1.44$ & $1-5$ & 0.6835 & 0.9317 \\
\hline 14 & Feeling that life no longer has meaning or purpose & $1.85 \pm 1.21$ & $1-5$ & 0.7166 & 0.9312 \\
\hline 15 & $\begin{array}{l}\text { Feeling that I have not made a meaningful and lasting } \\
\text { contribution during my lifetime }\end{array}$ & $2.19 \pm 1.29$ & $1-5$ & $0.78 \mid 4$ & $0.930 \mathrm{I}$ \\
\hline 16 & $\begin{array}{l}\text { Feeling I have "unfinished business" (eg, things left unsaid, } \\
\text { or incomplete) }\end{array}$ & $2.34 \pm 1.30$ & $1-5$ & 0.6435 & 0.9323 \\
\hline $17^{*}$ & Concern that my spiritual life is not meaningful & $1.57 \pm 1.06$ & $1-5$ & 0.5126 & 0.9343 \\
\hline 18 & Feeling that I am a burden to others & $2.20 \pm 1.45$ & $1-5$ & 0.6518 & 0.9322 \\
\hline 19 & Feeling that I don't have control over my life & $2.11 \pm 1.39$ & $1-5$ & 0.7977 & 0.9298 \\
\hline 20 & $\begin{array}{l}\text { Feeling that my illness and care needs have reduced my } \\
\text { privacy }\end{array}$ & $1.91 \pm 1.24$ & $1-5$ & 0.5859 & 0.9332 \\
\hline 21 & $\begin{array}{l}\text { Not feeling supported by my community of friends and } \\
\text { family }\end{array}$ & $1.90 \pm 1.23$ & $1-5$ & 0.6024 & 0.9330 \\
\hline 22 & Not feeling supported by my health care providers & $1.54 \pm 1.00$ & $1-5$ & 0.4194 & 0.9357 \\
\hline 23 & $\begin{array}{l}\text { Feeling like I am no longer able to mentally "fight" the } \\
\text { challenges of my illness }\end{array}$ & $1.70 \pm 1.12$ & $\mathrm{I}-5$ & 0.6842 & 0.9317 \\
\hline 24 & Not being able to accept the way things are & $1.96 \pm 1.28$ & $1-5$ & 0.6750 & 0.9318 \\
\hline 25 & Not being treated with respect or understanding by others & $1.89 \pm 1.24$ & $1-5$ & 0.6735 & 0.9319 \\
\hline Tota & & $48.27 \pm 19.59$ & $25-125$ & - & 0.9351 \\
\hline
\end{tabular}

Note: *Items modified.

Abbreviations: PDI, Patient Dignity Inventory; SD, standard deviation; Min, minimum; Max, maximum.

Successively, from the initial factors, we selected the first three factors that explained $>80 \%$ of the cumulative variance, with an eigenvalue $>1$ according to the Kaiser's criterion, and a significant discontinuity from the following factors at scree plot (Figure 1). At the orthogonal rotation (varimax), the items that underlie the three factors with factor loadings $>0.40$ and uniqueness $<0.70$ were chosen (Table 5). Among items that presented factor loadings $>0.40$ on more than one factor (Nos 7, 9, 11, 12, 19, 24 and 25), we choose those with the highest factor loading to identify the factor supported, as shown in Table 5 . From our model, item Nos 3 ("Addressing physically disturbing symptoms resulting from side effects of drugs") and 22 ("Do not feel the support of health workers") were excluded because they did not support any factor, showing factor loading $<0.40$ (low relevant in defining the factor's dimensionality) and uniqueness $>0.70$ (low relevant in the factor model since the variance of these items was greatly shared with others) (Table 5). This result was further confirmed by the item-scale correlations of item Nos 3 and 22, which were the lowest among all the PDI items, as shown in Table 3. The three factors, labeled as follows, showed good internal consistency as measured by Cronbach's alpha coefficient (Table 5):

Factor 1: Loss of self-identity and social role (Cronbach's alpha coefficient $=0.89$ ), loaded by 13 items:

10. Not being able to continue with my usual routines 
Table 4 Initial factor loading for the PDI

\begin{tabular}{llll}
\hline Initial factors & Eigenvalues & Proportion & Cumulative \\
\hline Factor I & 9.82 & 0.64 & 0.64 \\
Factor 2 & 1.53 & 0.1 & 0.73 \\
Factor 3 & 1.14 & 0.07 & 0.81 \\
Factor 4 & 0.86 & 0.05 & 0.86 \\
Factor 5 & 0.61 & 0.04 & 0.90 \\
Factor 6 & 0.61 & 0.04 & 0.90 \\
Factor 7 & 0.53 & 0.03 & 0.97 \\
Factor 8 & 0.40 & 0.02 & 1.00 \\
Factor 9 & 0.37 & 0.02 & 1.02 \\
Factor 10 & 0.32 & 0.02 & 1.05
\end{tabular}

Abbreviation: PDI, Patient Dignity Inventory.

12. Not feeling worthwhile or valued

13. Not being able to carry out important roles (eg, spouse, parent)

14. Feeling that life no longer has meaning or purpose

15. Feeling that I have not made a meaningful and lasting contribution during my lifetime

16. Feeling I have "unfinished business" (eg, things left unsaid, or incomplete)

17. Concern that my spiritual life is not meaningful

18. Feeling that I am a burden to others

19. Feeling that I don't have control over my life

20. Feeling that my illness and care needs have reduced my privacy

21. Not feeling supported by my community of friends and family

23. Feeling like I am no longer able to mentally "fight" the challenges of my illness

25. Not being treated with respect or understanding by others

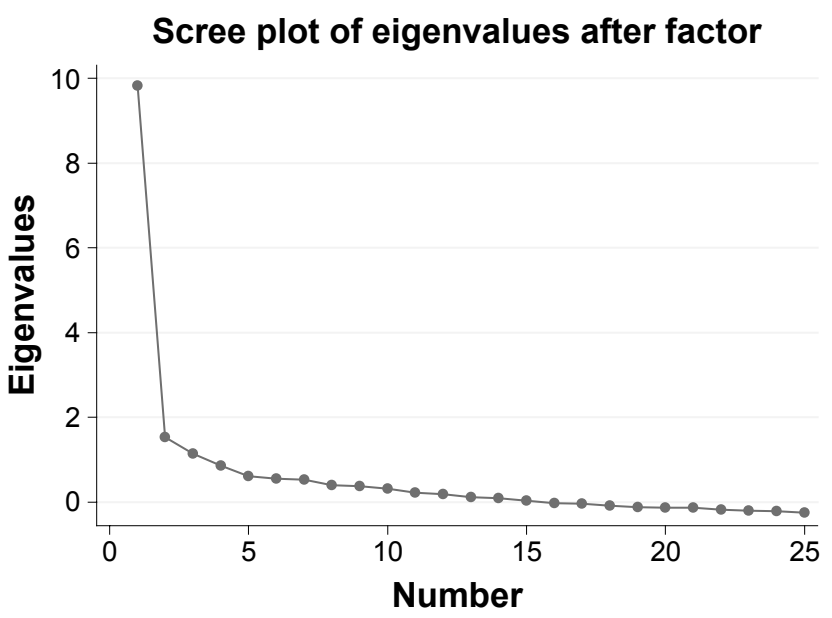

Figure I Scree plot of the factorial analysis: eigenvalues of the PDI items. Abbreviation: PDI, Patient Dignity Inventory.
Factor 2: Anxiety and uncertainty for future (Cronbach's alpha coefficient $=0.86$ ), loaded by seven items:

4. Feeling that how I look to others has changed significantly

5. Feeling depressed

6. Feeling anxious

7. Feeling uncertain about my illness and treatment

8. Worrying about my future

11. Feeling like I am no longer who I was

24. Not being able to accept the way things are

Factor 3: Loss of personal autonomy (Cronbach's alpha coefficient $=0.78)$, loaded by three items:

1. Not being able to carry out tasks associated with daily living (eg, washing myself, getting dressed)

2. Not being able to attend to my bodily function independently (eg, needing assistance with toiletingrelated activities)

9. Not being able to think clearly.

We obtained a value of 0.87 at the KMO test (range between 0 and 1), which permitted us to define our sample "meritorious", since it was numerically adequate for factor analysis. Bartlett's test of sphericity (Chi-square =1,732.56; $d f=300 ; P=0.000)$ showed that items were not intercorrelated.

The oblique rotation substantially confirmed the orthogonal rotation results, suggesting that the same three main factors were positively and partially related to each other (Table 6).

The analysis of concurrent validity showed a statistically significant positive correlation between the total score of the PDI and its three factors and the Ham-A and Ham-D scale scores, but not with other scales, as shown in Table 7 , indicating that the dimensions investigated by PDI and other validated scales consisted of depression and anxiety. In our sample, HAM-D and Ham-A scores indicated mild to moderate severity of anxiety and depression as well as PDI score, which showed similar degree of dignity loss.

\section{Discussion}

Our sample, despite suffering mostly from chronic and severe disorders, showed a good response rate (93\%), confirming the comprehensibility and applicability of the questionnaire to psychiatric setting as well as to other settings different from the oncologic field. ${ }^{42,43}$

Our research confirmed the reliability and excellent internal consistency of the PDI also when implemented in psychiatry, as evidenced by a value of Cronbach's 
Table 5 Rotated factor loadings and unique variances in the PDI factorial analysis

\begin{tabular}{|c|c|c|c|c|c|}
\hline \multicolumn{2}{|c|}{ Items } & $\begin{array}{l}\text { Factor I } \\
\text { "Loss of self-identity } \\
\text { and social role" }\end{array}$ & $\begin{array}{l}\text { Factor } 2 \\
\text { "Anxiety and } \\
\text { uncertainty for future" }\end{array}$ & \multirow{2}{*}{$\begin{array}{l}\text { Factor } 3 \\
\text { "Loss of personal } \\
\text { autonomy" } \\
\mathbf{0 . 8 2 8 3}\end{array}$} & \multirow{2}{*}{$\begin{array}{l}\text { Uniqueness } \\
0.3067\end{array}$} \\
\hline 1 & $\begin{array}{l}\text { Not being able to carry out tasks associated } \\
\text { with daily living }\end{array}$ & 0.0793 & 0.0321 & & \\
\hline 2 & $\begin{array}{l}\text { Not being able to attend to my bodily } \\
\text { function independently }\end{array}$ & 0.1011 & 0.1871 & 0.8033 & 0.3094 \\
\hline $3^{*}$ & $\begin{array}{l}\text { Experiencing physically distressing symptoms } \\
\text { as drug adverse effects }\end{array}$ & 0.1206 & 0.3599 & 0.3376 & 0.7419 \\
\hline 4 & $\begin{array}{l}\text { Feeling that how I look to others has changed } \\
\text { significantly }\end{array}$ & 0.2000 & 0.5264 & 0.3025 & 0.5914 \\
\hline 5 & Feeling depressed & 0.1893 & 0.7840 & 0.0394 & 0.3479 \\
\hline 6 & Feeling anxious & 0.1700 & 0.8044 & 0.1030 & 0.3135 \\
\hline 7 & $\begin{array}{l}\text { Feeling uncertain about my illness and } \\
\text { treatment }\end{array}$ & 0.4673 & 0.4836 & 0.2180 & 0.5001 \\
\hline 8 & Worrying about my future & 0.3844 & 0.5700 & 0.0681 & 0.5227 \\
\hline 9 & Not being able to think clearly & 0.4348 & 0.2992 & 0.5345 & 0.4357 \\
\hline 10 & $\begin{array}{l}\text { Not being able to continue with my usual } \\
\text { routines }\end{array}$ & 0.4955 & 0.1358 & 0.1125 & 0.7234 \\
\hline II & Feeling like I am no longer who I was & 0.4092 & 0.4944 & 0.3125 & 0.4904 \\
\hline 12 & Not feeling worthwhile or valued & 0.4953 & 0.4229 & 0.2323 & 0.5218 \\
\hline 13 & $\begin{array}{l}\text { Not being able to carry out important roles } \\
\text { (eg, spouse, parent) }\end{array}$ & 0.4501 & 0.3312 & 0.3162 & 0.5878 \\
\hline 14 & $\begin{array}{l}\text { Feeling that life no longer has meaning } \\
\text { or purpose }\end{array}$ & 0.6446 & 0.3913 & 0.1182 & 0.4174 \\
\hline 15 & $\begin{array}{l}\text { Feeling that I have not made a meaningful and } \\
\text { lasting contribution during my lifetime }\end{array}$ & 0.7538 & 0.3984 & 0.0869 & 0.2655 \\
\hline 16 & $\begin{array}{l}\text { Feeling I have "unfinished business" } \\
\text { (eg, things left unsaid, or incomplete) }\end{array}$ & 0.5583 & 0.3026 & 0.2011 & 0.5563 \\
\hline $17^{*}$ & $\begin{array}{l}\text { Concern that my spiritual life is not } \\
\text { meaningful }\end{array}$ & 0.5716 & 0.0656 & 0.0430 & 0.6672 \\
\hline 18 & Feeling that I am a burden to others & 0.4143 & 0.3836 & 0.2904 & 0.5968 \\
\hline 19 & Feeling that I don't have control over my life & 0.5581 & 0.5385 & 0.3327 & 0.2878 \\
\hline 20 & $\begin{array}{l}\text { Feeling that my illness and care needs have } \\
\text { reduced my privacy }\end{array}$ & 0.4493 & 0.2601 & 0.2710 & 0.6570 \\
\hline 21 & $\begin{array}{l}\text { Not feeling supported by my community of } \\
\text { friends and family }\end{array}$ & 0.5846 & 0.0381 & $0.3|4|$ & 0.5582 \\
\hline 22 & $\begin{array}{l}\text { Not feeling supported by my health care } \\
\text { providers }\end{array}$ & 0.3592 & 0.0182 & 0.3280 & 0.7631 \\
\hline 23 & $\begin{array}{l}\text { Feeling like I am no longer able to mentally } \\
\text { "fight" the challenges of my illness }\end{array}$ & 0.6882 & 0.3595 & 0.0483 & 0.3948 \\
\hline 24 & Not being able to accept the way things are & 0.4163 & 0.5470 & 0.2212 & 0.4785 \\
\hline 25 & $\begin{array}{l}\text { Not being treated with respect or } \\
\text { understanding by others }\end{array}$ & 0.5775 & 0.1247 & 0.4351 & 0.4616 \\
\hline
\end{tabular}

Notes: *Items modified. Items in bold: $>0.40$ factor loading; items in italic: $>0.70$ uniqueness.

Abbreviation: PDI, Patient Dignity Inventory.

alpha coefficient (0.93) similar to that obtained in most validation studies. ${ }^{36,39-43}$ The factor analysis revealed three factors that overlapped most dimensions identified by all other validation studies, ${ }^{36,41-43}$ with the exception of the Italian study that identified only one significant factor. ${ }^{39}$ Factor 1

Table 6 Correlation matrix of the promax rotated common factors

\begin{tabular}{llll}
\hline Factors & Factor I & Factor 2 & Factor 3 \\
\hline Factor I & $\mathrm{I}$ & & \\
Factor 2 & 0.576 & $\mathrm{I}$ & \\
Factor 3 & 0.565 & 0.432 & $\mathrm{I}$ \\
\hline
\end{tabular}

was composed of the greatest number of items with the highest internal consistence and included items related to the maintenance of both self-identity and social role, indicating that individual and social aspects of dignity can be violated in distress situations such as a severe disease. We suggested that our Factor 1, "Loss of self-identity and social role", overlapped almost completely three factors of the Chochinov validation study, ${ }^{36}$ Existential Distress, Peace of Mind and Social Support, Factors 1 (Psychological and Existential Distress) and 3 (Social Support) of the Spanish validation study, ${ }^{41}$ and was almost completely similar to Factor 1 (Loss of Sense of Worth and Meaning) of both the German ${ }^{40}$ 
Table 7 Correlations of PDI and the three factors identified with other scales

\begin{tabular}{|c|c|c|c|c|}
\hline Scales & $\begin{array}{l}\text { PDI } \\
(\mathrm{m}=48.27 \pm(9.59 \mathrm{SD})\end{array}$ & $\begin{array}{l}\text { Factor } I \\
(m=21.37 \pm 9.79 \text { SD) }\end{array}$ & $\begin{array}{l}\text { Factor } 2 \\
(m=14.59 \pm 6.72 S D)\end{array}$ & $\begin{array}{l}\text { Factor } 3 \\
(m=4.76 \pm 2.73 \mathrm{SD})\end{array}$ \\
\hline \multicolumn{5}{|c|}{$\mathrm{Ham}-\mathrm{D}(\mathrm{m} \pm \mathrm{SD})$} \\
\hline \multirow[t]{2}{*}{$14.20 \pm 7.58$} & $\begin{array}{l}\text { Spearman's rho }=0.33 \\
(P=0.0005)\end{array}$ & $\begin{array}{l}\text { Spearman's rho }=0.28 \\
(P=0.0034)\end{array}$ & $\begin{array}{l}\text { Spearman's rho }=0.28 \\
(P=0.0032)\end{array}$ & $\begin{array}{l}\text { Spearman's rho }=0.3 \mathrm{I} \\
(P=0.00 \mathrm{II})\end{array}$ \\
\hline & $\begin{array}{l}\text { Kendall's score }=1,259 \\
(P=0.005)\end{array}$ & $\begin{array}{l}\text { Kendall's score }=\mid, 021 \\
(P=0.0046)\end{array}$ & $\begin{array}{l}\text { Kendall's score }=1,077 \\
(P=0.0028)\end{array}$ & $\begin{array}{l}\text { Kendall's score }=1,062 \\
(P=0.0015)\end{array}$ \\
\hline \multicolumn{5}{|c|}{ Ham-A $(m \pm S D)$} \\
\hline \multirow[t]{2}{*}{$9.90 \pm 6.70$} & $\begin{array}{l}\text { Spearman's rho }=0.3075 \\
(P=0.0014)\end{array}$ & $\begin{array}{l}\text { Spearman's rho }=0.28 \\
(P=0.0036)\end{array}$ & $\begin{array}{l}\text { Spearman's rho }=0.26 \\
(P=0.0069)\end{array}$ & $\begin{array}{l}\text { Spearman's rho }=0.23 \\
(P=0.0203)\end{array}$ \\
\hline & $\begin{array}{l}\text { Kendall's score }=I, 156 \\
(P=0.00 \mid 3)\end{array}$ & $\begin{array}{l}\text { Kendall's score }=1,029 \\
(P=0.0043)\end{array}$ & $\begin{array}{l}\text { Kendall's score }=970 \\
(P=0.007)\end{array}$ & $\begin{array}{l}\text { Kendall's score }=1,080 \\
(P=0.0027)\end{array}$ \\
\hline
\end{tabular}

Abbreviations: PDI, Patient Dignity Inventory; m, mean; SD, standard deviation; Ham-D, Hamilton Rating Scale for Depression; Ham-A, Hamilton Anxiety Rating Scale.

and the Iranian studies ${ }^{42}$ (Loss of Human Dignity). In these two last validation research, Factor 1 was supported by the highest number of items and presented good-to-excellent internal consistence as well as in our study.

Our Factor 2, "Anxiety and uncertainty for future", presented the psychological aspects related to illness, such as anxiety, depression, uncertainty for future, helplessness and hopelessness. It overlapped the Factor Symptom Distress (with the exception of the item related to physical symptoms) and some items of Existential Distress of the Chochinov validation study, some items of Factor 1 of the Spanish study, Psychological and Existential Distress, almost completely Factor 2 of the German study, which shared the same label and Factor 2 of the Iranian study, Emotional Distress and Uncertainty.

Our Factor 3, "Loss of personal autonomy" completely overlapped Dependency (with the exception of one item of Symptom Distress) among the factors identified in the Chochinov study and Factor 3 of both the German and the Iranian studies, whose labels were similar. Differently, in the Spanish validation study, the items that supported our Factor 3 presented higher factor loadings in Factor 2, Physical Symptoms and Dependence.

The items related to somatic concerns ("the tolerance of the side effects of drugs") and the health care professional support ("do not feel the support of health workers") did not load any factor in our analysis. This result, which is different from all other validation studies, could suggest the good functionality of the PDI for detecting specific dimensions and characteristics of psychiatric disorders. In fact, all these two items identify problematic issues in psychiatric field: physical symptoms are not typical of psychiatric disorders, especially psychosis, which, on the contrary, are often characterized by the "denial of illness" or "distortion of symptoms" and the lack of awareness regarding disease $;{ }^{61}$ establishing therapeutic relationships, which is considered a "predictor of outcome" in psychiatric setting, is often difficult for our patients due to the altered relationships and social maladjustment directly related to many psychiatric diseases, especially in an acute phase of illness. ${ }^{62}$ In accordance with the earlier reported studies, our factor analysis suggested that the experience of dignity, which can be jeopardized by illness, is composed of three main psychological dimensions: 1) existential distress related to both self-identity and social role, 2) anxiety and uncertainty for future and 3) loss of autonomy in personal activities and thoughts. Moreover, our three-factor model was largely comparable to the three main areas first identified by Chochinov, ${ }^{36}$ as shown in Figure 2, indicating that, also in psychiatry, three psychological dimensions can condition the patient perception of dignity. From our model, we can infer that loss of autonomy in activities and thinking is closely related to illness as well as the feelings of anxiety and uncertainty for future, whereas the fear of losing the continuity of self and social status can constitute the core part of dignity. In fact, this dimension, represented by Factor 1, was the biggest one, loaded by the highest number of PDI items with the highest internal consistence in comparison with the other two factors, indicating that "Loss of self-identity and social role" was the most potentially detrimental dimensions for dignity, closely followed by "Anxiety and uncertainty about the future" and "Loss of personal autonomy". We hypothesize that, especially in the most severe diseases, both the continuity of self and social status of individuals can be undermine, inducing feelings of hopelessness and helplessness and fear of dependency, which, all together, can strongly compromise personal and social dignity. Our study as well as other research among patients affected by different pathologies ${ }^{42,43}$ suggest the specificity of the PDI in detecting the universality of dignity that can be interpreted as a sort of "interface" between patients and others altered 


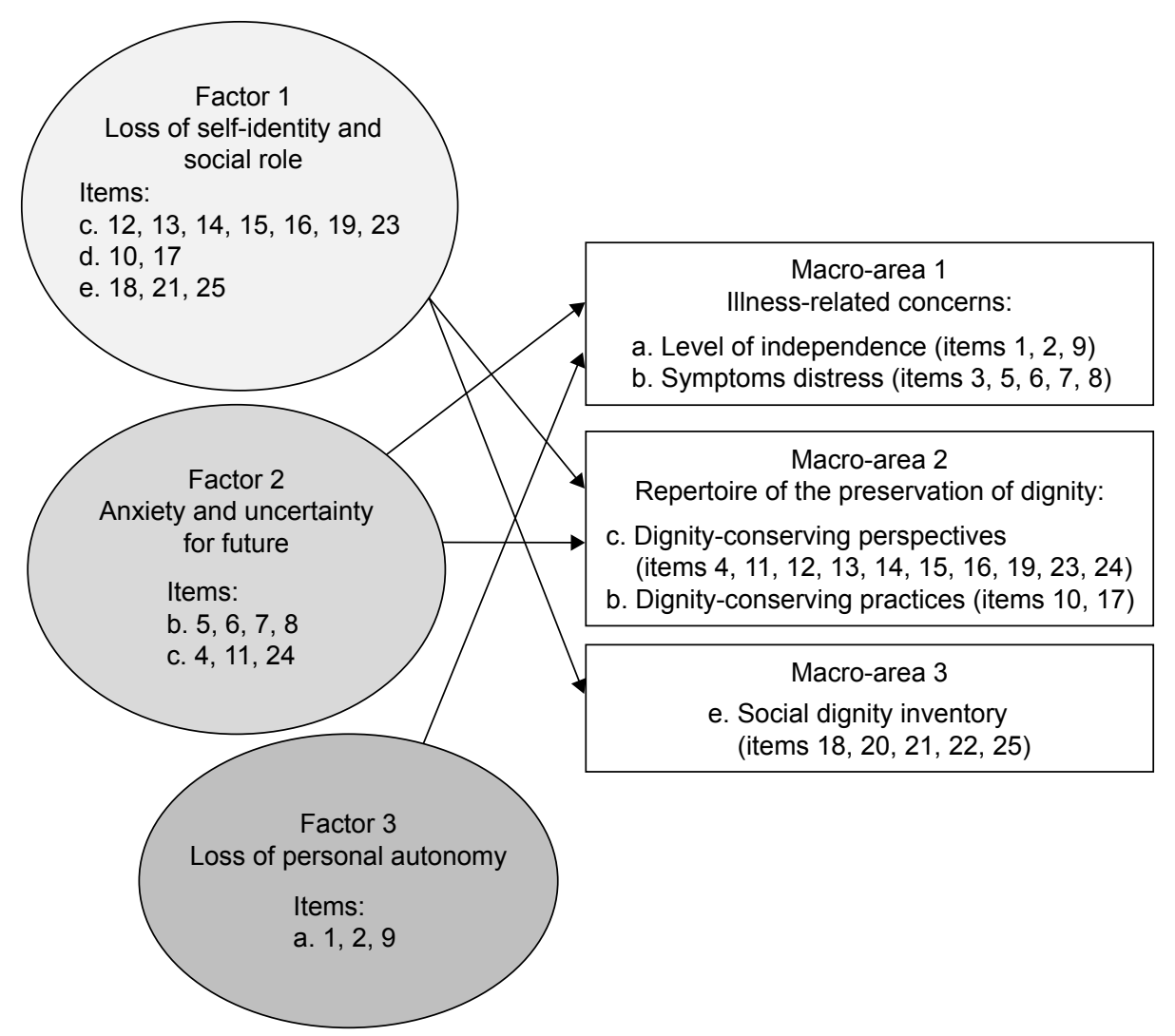

Figure 2 Plot of the correspondence between the three factors identified and the three Chochinov's macro-areas.

by regressive and disruptive illness conditions. This result was further confirmed by the positive correlation of the PDI and the three-factor scores with the depression and anxiety scale scores, indicating that the areas investigated were largely although not completely overlapped. This significant correlation provided concurrent validity of the PDI applied to psychiatry. In this regard, in line with another study, we highlighted that patients showed worsened perception of dignity when they felt anxious and depressed, symptoms conditioned by many kinds of severe and disabling illnesses, including psychiatric disorders. We have to underline that, in most of our cases, "anxiety and uncertainty for future" were not related only to depressive disorders, since our patients suffered from many different psychiatric diseases. In this regard, we can infer that these symptoms were related not only to a specific diagnosis but also to the condition of hospitalization, which, even if necessary, can potentially induce a dramatic disruption of previous living habits and can lead the patients to be dramatically aware of their inability to live independently. Hospitalization can represent a deprivation of patients' liberty and privacy since they have to adhere to pre-defined therapeutic activities, to share spaces with others and to be subject to ward rules, especially in case of involuntary admission. ${ }^{20,21,35}$ Nevertheless, these same restrictive conditions can incentivize cooperation with professionals and favor the recovery process.

Our preliminary investigation highlights that PDI was easy to administer for professionals and to understand for patients, regardless of their education level and disabilities. It was a useful tool to quantify the patients' subjective experience of hospitalization and treatment, providing their personal feedback. Among our patients, the PDI was generally well appreciated, probably because it was seen as a sign of professionals' interest in their problems. This observation indicates that the PDI can be useful to improve therapeutic relationship and increase patients' adherence to treatments and, indirectly, the positive outcome of treatments. ${ }^{19,21}$ According to our research, PDI can represent a useful tool for both professionals and patients, permitting us to reflect on the health care provided and, in the meantime, improving the ethical aspects of the therapeutic relationship. Therefore, we can suggest to implement it at discharge of hospitalization as a feedback of caring and treatment, in order to promote the improvement of the quality of care.

Moreover, the questionnaire allows us to focus our attention on the concept of dignity in psychopathological context, 
indicating that, also in this field, more than one dimension contributes to forming its personal experience, in analogy to the historical and philosophical concept of dignity. In light of our results, we suggest that dignity can be the resultant of many overlapped factors belonging to both the internal and the external world of patients.

\section{Study limitations}

The first limitation of the study is represented by the relatively limited sample size, even if sufficiently adequate to perform the factor analysis according to the index of KMO described earlier. Another limitation can be constituted by the heterogeneity of psychiatric disorders in our sample as well as the time of PDI administration just before discharge that could have conditioned our outcome. We must emphasize that this is a preliminary study, aimed at the initial administration and validation of the PDI in a psychiatric setting. Additional research on a larger number of patients, among other psychiatric settings, such as facilities for disabling disorders, for example, is necessary in order to confirm the validation of PDI and to analyze the predictive validity of PDI among psychiatric patients.

\section{Conclusion}

Our survey suggests that the PDI can be a reliable and valuable tool to measure the subjective perception of dignity among patients admitted to the psychiatric ward, until now little investigated. From our factor analysis, we suggest that the perception of dignity is impacted by various psychological dimensions related to the areas of self and relationships with others, which can be strongly disrupted by severe and disabling illness conditions, including psychiatric diseases.

The PDI was well accepted by our patients, who responded with excellent participation, demonstrating a correct understanding of the questionnaire and the underlining concept of dignity. Its easy administration and compilation can be a further incentive to promote it in psychiatry to improve therapeutic relationship and indirectly the outcome of treatment.

We conclude by saying that care and cure without dignity cannot be effective, especially in psychiatry, where prejudice and stigma are still the major obstacles to understanding patients and fostering their full social reintegration.

\section{Acknowledgment}

The authors would like to thank the patients for their participation in the study. The authors express their special thanks to Prof Harvey Max Chochinov for his kind support and advice in this research.

\section{Disclosure}

The authors report no conflicts of interest in this work.

\section{References}

1. Crosato C. L'uguale dignità degli uomini. Per una riconsiderazione del fondamento di una politica morale [The Equal Dignity of Human Beings. A Reconsideration of the Basis of a Political Morality]. Assisi: Cittadella; 2013.

2. Lombardi Ricci M, Zeppegno G. Dignità umana. Dialoghi interdisciplinari: filosofia, scienza e società [Human Dignity. Interdisciplinary Dialogues: Philosophy, Science and Society]. Torino: Effatà; 2016.

3. Rosen M. Dignità. Storia e significato [Dignity. History and Meaning]. Torino: Codice; 2013

4. Casaburi N. Il cammino della dignità. Peripezie, fascino, manipolazioni di una parola [The Path of Dignity. Vicissitudes, Enchantment, Manipulation of a Word]. Roma: Ediesse; 2015.

5. Salvati M, Bovero M, Costa P, Donolo C. Dichiarazione universale dei diritti dell'uomo: 10 dicembre 1948. Nascita, declino e sviluppi [Universal Declaration of Human Rights: 10 December 1948 Birth, Decline and Developments]. 2nd ed. Roma: Ediesse; 2006.

6. Flick GM. Elogio della dignità [In Praise of Dignity]. Roma: Libreria Editrice Vaticana; 2015.

7. Eriksson K. Caring science in a new key. Nurs Sci Q. 2002; 15(1):61-65.

8. Nordenfelt L. The varieties of dignity. Health Care Anal. 2004; 12(2):69-81.

9. Jacobson N. Dignity violation in health care. Qual Health Res. 2009; 19(11):1536-1547.

10. León FJ. The law of rights and duties of persons in health care from the viewpoint of bioethics. Rev Med Chil. 2012;140(11):1490-1494.

11. Jacobson N. A taxonomy of dignity: a grounded theory study. BMC Int Health Hum Rights. 2009;9:3.

12. Beach MC, Sugarman J, Johnson RL, Arbelaez JJ, Duggan PS, Cooper LA. Do patients treated with dignity report higher satisfaction, adherence, and receipt of preventive care? Ann Fam Med. 2005;3(4): 331-338.

13. Lin YP, Watson R, Tsai YF. Dignity in care in the clinical setting: a narrative review. Nurs Ethics. 2013;20(2):168-177.

14. Ferri P, Muzzalupo J, Di Lorenzo R. Patients' perception of dignity in an Italian general hospital: a cross-sectional analysis. BMC Health Serv Res. 2015;15:41.

15. Bostrom N. In defense of posthuman dignity. Bioethics. 2005;19(3): 202-214.

16. Turoldo F. Bioetica ed etica della responsabilità. Dai fondamenti teorici alle applicazioni pratiche [Bioethics and Ethics of Responsibility. From Theoretical Foundations to Practical Applications]. Assisi: Cittadella; 2009.

17. Chochinov HM, Hack T, McClement S, Kristjanson L, Harlos M. Dignity in the terminally ill: a developing empirical model. Soc Sci Med. 2002;54(3):433-443.

18. Widäng I, Fridlund B. Self-respect, dignity and confidence: conceptions of integrity among male patients. $J$ Adv Nurs. 2003;42(1):47-56.

19. Lohne V, Aasgaard T, Caspari S, Slettebø A, Nåden D. The lonely battle for dignity: individuals struggling with multiple sclerosis. Nurs Ethics. 2010;17(3):301-311.

20. Fukujama F. Our Posthuman Future: Consequences of the Biotechnology Revolution. Arezzo: Picador; 2002.

21. Bhugra D, Ventriglio A, Pathare S. Freedom and equality in dignity and rights for persons with mental illness. Lancet Psychiatry. 2016;3(3): 196-197. 
22. World Health Organization [webpage on the Internet]. World Mental Health Day 2015. Dignity and Mental Health. 2015. Available from: http://www.who.int/mental_health/world-mental-health-day/2015/en/. Accessed August 24, 2016.

23. Bramesfeld A, Wedegärtner F, Elgeti H, Bisson S. How does mental health care perform in respect to service users' expectations? Evaluating inpatient and outpatient care in Germany with the WHO responsiveness concept. BMC Health Serv Res. 2007;7:99.

24. Bloch S, Green SA. An ethical framework for psychiatry. Br J Psychiatry. 2006;188:7-12.

25. Burns JK. Mental health and inequity: a human rights approach to inequality, discrimination, and mental disability. Health Hum Rights. 2009;11(2):19-31.

26. Stoecker R. Philosophy of human dignity and the ethics of psychiatry. Psychiatr Prax. 2014;41(suppl 1):S19-S25.

27. Saxena S, Hanna F. Dignity-a fundamental principle of mental health care. Indian J Med Res. 2015;142(4):355-358.

28. Appelbaum PS. Protecting the rights of persons with disabilities: an international convention and its problems. Psychiatr Serv. 2016;67(4): 366-368.

29. Kleintjes S, Lund C, Swartz L. Barriers to the participation of people with psychosocial disability in mental health policy development in South Africa: a qualitative study of perspectives of policy makers, professionals, religious leaders and academics. BMC Int Health Hum Rights. 2013;13:17.

30. Righi L, Pallassini M, Lastrucci D. Metodiche operative per la valutazione e la salvaguardia della dignità del paziente: analisi della letteratura [Operating procedure for the evaluation and preservation of patient dignity: analysis of the literature]. L'infermiere. 2013;50:5-9.

31. Lindwall L, Boussaid L, Kulzer S, Wigerblad A. Patient dignity in psychiatric nursing practice. J Psychiatr Ment Health Nurs. 2012;19(7): 569-576.

32. Skorpen F, Thorsen AA, Forsberg C, Rehnsfeldt AW. Suffering related to dignity among patients at a psychiatric hospital. Nurs Ethics. 2014;21(2):148-162.

33. Gustafsson LK, Wigerblad A, Lindwall L. Respecting dignity in forensic care: the challenge faced by nurses of maintaining patient dignity in clinical caring situations. J Psychiatr Ment Health Nurs. 2013;20(1):1-8.

34. Gustafsson LK, Wigerblad A, Lindwall L. Undignified care: violation of patient dignity in involuntary psychiatric hospital care from a nurse's perspective. Nurs Ethics. 2014;21(2):176-186.

35. Chochinov HM, Hack T, Hassard T, Kristjanson LJ, McClement S, Harlos M. Dignity therapy: a novel psychotherapeutic intervention for patients near the end of life. J Clin Oncol. 2005;23(24):5520-5525.

36. Chochinov HM, Hassard T, McClement S, et al. The patient dignity inventory: a novel way of measuring dignity-related distress in palliative care. J Pain Symptom Manage. 2008;36(6):559-571.

37. Chochinov HM. Dignity and the essence of medicine: the A, B, C, and D of dignity conserving care. BMJ. 2007;335(7612):184-187.

38. Albers G, Pasman HR, Rurup ML, de Vet HC, Onwuteaka-Philipsen BD. Analysis of the construct of dignity and content validity of the patient dignity inventory. Health Qual Life Outcomes. 2011;9:45.

39. Ripamonti CI, Buonaccorso L, Maruelli A, et al. Patient dignity inventory (PDI) questionnaire: the validation study in Italian patients with solid and hematological cancers on active oncological treatments. Tumori. 2012;98(4):491-500.

40. Sautier LP, Vehling S, Mehnert A. Assessment of patients' dignity in cancer care: preliminary psychometrics of the German version of the Patient Dignity Inventory (PDI-G). J Pain Symptom Manage. 2014;47(1): $181-188$.
41. Rullán M, Carvajal A, Núñez-Córdoba JM, et al. Spanish version of the patient dignity inventory: translation and validation in patients with advanced cancer. J Pain Symptom Manage. 2015;50(6):874-881.

42. Abbaszadeh A, Borhani F, Rabori MR. Patient dignity in coronary care: psychometrics of the Persian version of the patient dignity inventory. Br J Med Med Res. 2015;8(5):463-469.

43. Chochinov HM, Johnston W, McClement SE, et al. Dignity and distress towards the end of life across four non-cancer populations. PLoS One. 2016;11(1):e0147607.

44. Babalola O, Gormez V, Alwan NA, Johnstone P, Sampson S. Length of hospitalization for people with severe mental illness. Cochrane Database Syst Rev. 2014;1:CD000384.

45. Di Lorenzo R, Sagona M, Landi G, Martire L, Piemonte C, Del Giovane C. The revolving door phenomenon in an Italian Acute Psychiatric Ward: a 5-year retrospective analysis of the potential risk factors. J Nerv Ment Dis. 2016;204(9):686-692.

46. Hamilton M. A rating scale for depression. JNeurol Neurosurg Psychiatry. 1960;23:56-62.

47. Hamilton M. The assessment of anxiety states by rating. $\mathrm{Br} \mathrm{J}$ Med Psychol. 1959;32(1):50-55.

48. Aas IHM. Guidelines for rating Global Assessment of Functioning (GAF). Ann Gen Psychiatry. 2011;10:2.

49. Lora A, Bai G, Binachi S, et al. The Italian version of HoNOS (Health of the Nation Outcome Scales), a scale for evaluating the outcomes and the severity in mental health services. Epidemiol Psichiatr Soc. 2001; 10(3):198-204.

50. Hatcher L. A Step-by-Step Approach to Using the SAS ${ }^{\circledR}$ System for Factor Analysis and Structural Equation Modeling. Cary, NC: SAS Institute; 1994.

51. Bryant FB, Yarnold PR. Principal components analysis and exploratory and confirmatory factor analysis. In: Grimm LG, Yarnold RR, editors. Reading and Understanding Multivariale Statistics. Washington, DC: American Psychological Association; 1995:99-136.

52. Folstein MF, Flostein SE, McHugh PR. Mini-Mental State”. A practical method for grading the cognitive state of patients for the clinician. J Psychiatr Res. 1975;12:189-198.

53. Ministero del lavoro, della salute e delle politiche sociali. International Classification of Diseases, 9th Revision, Clinical Modification. Italian Version. Roma: Istituto poligrafico e Zecca dello Stato, Libreria dello Stato; 2008

54. Cureton EE, D’Agostino RB. Factor Analysis: An Applied Approach. Hillsdale, NJ: Erlbaum; 1983.

55. Acock AC. A Gentle Introduction to Stata. 3rd ed. College Station, TX: Stata Press; 2010.

56. Crawford CB, Ferguson GA. A general rotation criterion and its use in orthogonal rotation. Psychometrika. 1970;35(3):321-332.

57. Bentler PM. Factor simplicity index and transformations. Psychometrika. 1977;42(2):277-295.

58. Kaiser HF. An index of factor simplicity. Psychometrika. 1974; 39(1):31-36

59. Kaiser HF. The application of electronic computers to factor analysis. Educ Psychol Meas. 1960;20:141-151.

60. StataCorp. Stata Statistical Software: Release 12. College Station, TX: StataCorp LP; 2011.

61. Resnik S. The Delusional Person: Bodily Feelings in Psychosis. London: Karnac Books; 2001.

62. Priebe $\mathrm{S}, \mathrm{McCabe} \mathrm{R}$. Therapeutic relationships in psychiatry: the basis of therapy or therapy in itself? Int Rev Psychiatry. 2008;20(6):521-526. 


\section{Publish your work in this journal}

Neuropsychiatric Disease and Treatment is an international, peerreviewed journal of clinical therapeutics and pharmacology focusing on concise rapid reporting of clinical or pre-clinical studies on a range of neuropsychiatric and neurological disorders. This journal is indexed on PubMed Central, the 'PsycINFO' database and CAS,

and is the official journal of The International Neuropsychiatric Association (INA). The manuscript management system is completely online and includes a very quick and fair peer-review system, which is all easy to use. Visit http://www.dovepress.com/testimonials.php to read real quotes from published authors.

Submit your manuscript here: http://www.dovepress.com/neuropsychiatric-disease-and-treatment-journal 